\title{
Applications of Zinc Oxide Nanorods as Photocatalyst for the Decontami- nation of Imidacloprid and Spirotetramat Residues in Water
}

\author{
S. Sathiyanarayanan, P.E. Ravi and A. Ramesh ${ }^{*}$ \\ Department of Analytical Chemistry, International Institute of Bio-technology and Toxicology (IIBAT), Padappai, \\ Chennai 601 301, Tamil Nadu, India
}

\begin{abstract}
Zinc oxide nanorods having the size 100 to $250 \mathrm{~nm}$ and 1 to $2 \mu \mathrm{m}$ length were prepared by reacting zinc acetate with triethanolamine. The structure of the nanorods was confirmed by scanning electron microscope analysis. Photocatalytic activity of zinc oxide nanorods on the new class of ketoenole and chloronicotinyl insecticides spirotetramat and imidacloprid was investigated. The decontamination effect of catalyst on the residues of spirotetramat and imidacloprid in water was studied at three different buffer solutions (4.0, 7.0 and 9.0). The catalytic reaction was measured under direct sunlight at two different concentration levels and the optimum concentration of catalyst required for the decontamination was also established by varying the amount of catalyst from 0.02 to $0.2 \mathrm{~g} / \mathrm{L}$. Residues are quantified by a high performance liquid chromatography UV method (HPLC-UV) and calculated the DT 50 and DT 90 from the dissipation data. The rate of the reaction showed first order kinetics in water. The addition of zinc oxide nanorods induced the photocatalytic reaction contributing significantly to the rapid dissipation of residues. Complete mineralization of the residues was confirmed by liquid chromatography electrospray tandem mass spectrometry (LC-ESI-MS/MS). The method has the limit of quantification $0.1 \mu \mathrm{g} / \mathrm{L}$ in water.
\end{abstract}

Keywords: Zinc oxide nanorods, Photocatalysis, Spirotetramat, Imidacloprid, LC-ESI-MS/MS.

\section{INTRODUCTION}

Pesticides are widely used in agriculture to bring down the pest infestations in the field eventually contributing to the problem of environmental contamination. Presence of agrochemical residues in water reservoirs and other environmental strata leads to environmental contamination and poses risk to the living organisms. Bayer Crop Science (India) introduced the spirotetramat (cis-3-(2, 5-dimethylphenyl)-8-methoxy-2-oxo-1-azaspiro [4.5] dec-3-en-4-yl ethyl carbonate; ketoenole insecticide) and Imidacloprid (1-[(6chloro-3-pyridyl)-methyl] - 2-nitroimidazolidin; chloronicotinyl insecticide) as combinational insecticides (480 SC formulation) for the control of broad spectrum of sucking pests in agriculture.

The literature shows different methods for the determination of imidacloprid residues in environmental samples with lower than the CODEX (maximum residue) limit [1]. Several reports are published for the determination of residues of imdacloprid in water and other environmental substrates including the application of titania as photocatalytic agent for the decontamination of residues. Photocatalytic degradation of imidacloprid in water was studied with heterogeneous catalysis $\mathrm{TiO}_{2}$ and homogeneous catalysis (by Photo-Fenton) under direct sunlight and UV irradiation [2-8]. The semiconductor oxides $\left(\mathrm{TiO}_{2}\right.$ and $\left.\mathrm{ZnO}\right)$ are found to be most effective in photocatalytic degradation of residue of organophosphorus pesticide in water [9]. Degradation of neonicotinoid

*Address correspondence to this author at the Department of Analytical Chemistry, International Institute of Bio-technology and Toxicology (IIBAT), Padappai, Chennai 601 301, Tamil Nadu, India;

E-mail: raamesh_a@yahoo.co.in insecticides using oxidation process, effect of ozone on $\mathrm{TiO}_{2}$ photocatalysis [10], the catalytic activity of $\mathrm{TiO}_{2}$ on imidacloprid and other environmental contaminants [11-15] are widely reported by different researchers. Typically heat treated kerolites are also used for the decontamination of residues of imidacloprid in water and reported the influence of temperature on the degradation [16]. A comparative study between zinc oxide nanoparticle and its nano-crystalline particles in degradation of methylene blue in water under the influence of UV rays shows relatively high photocatalytic degradation capacity of $\mathrm{ZnO}$ nanoparticles than the $\mathrm{ZnO}$ nano crystallines [17]. The zero valent metals with ultrasonic irradiation showed good potential in degradation of thimethoxam and imidacloprid residues in water [18]. To meet the requirement of very low detection levels of imidacloprid and other pollutants, several methods including liquid chromatography UV detection and the tandem mass spectrometry detections are reported [19-22].

However the data pertaining to the fate of spirotetramat and its residues in water and the information on the application of zinc oxide nanorods as catalyst is scarce. In view of the paucity of information, present study was conducted with an objective to establish the photocatalytic activity of zinc oxide nanorods in decontamination of residues of imidacloprid, spirotetramat in water. The effect of zinc oxide nanorods in photocatalysis as a reaction enhancer in degradation of residues was studied and the data has been confirmed by LC-ESI-MS/MS analysis.

\section{MATERIALS AND METHODS}

\section{Materials}

Reference analytical standards of spirotetramat purity $99.4 \%$, metabolite enol purity $99.4 \%$ and imidacloprid purity 
$98.6 \%$, the suspension concentration (SC) formulation of combinational insecticide were supplied by Bayer crop science limited, India. A composite solution of spirotetramat and imidacloprid reference standards was prepared by mixing aliquots of stock solution. From the stock solution prepared a series of calibration solutions by further dilution. Distilled water was purified by passing through the Milli-Q Plus apparatus (Millipore, Bedford, MA, USA). Acetonitrile HPLC gradient grade was obtained from Merck India limited. Zinc acetate and Triethanolamine supplied by Merck India limited are used in the preparation of nanorods. The other chemicals used are analytical grade reagents.

\section{Analysis of Spirotetramat and Imidacloprid Residues}

A Shimadzu prominence High Performance Liquid Chromatograph equipped with a UV detector was used for the quantification of residues of imidacloprid, spirotetramat and its metabolite enol. The detector wavelength $230 \mathrm{~nm}$ was used for the quantification of residues. The stationary phase Phenomenex $\mathrm{C} 18$ of $4.6 \mathrm{~mm}$ i.d. and $250 \mathrm{~mm}$ length was used for the separation of insecticides. The mobile phase used for the elution was a mixture of $400 \mathrm{ml}$ of acetonitrile and $600 \mathrm{ml}$ of $0.04 \%$ formic acid in Milli q water, the flow rate was programmed between 1.5 to $2.0 \mathrm{ml}$ per minute, the injection volume was $20 \mu \mathrm{l}$. The insecticides imidacloprid, metabolite enol and spirotetramat are eluted at 3.6 minutes; 5.8 minutes and 19.5 minutes retention times respectively.

For the confirmation purpose a High Capacity Ion Trap (HCT plus) LC-MS/MS System supplied by Bruker Daltonik $\mathrm{GmbH}$ was used. Drying gas and the nebulizing gas nitrogen was generated from the pressurized air using a Nitrox UHPLCMS nitrogen generator. The nebuliser gas flow was fixed to $10 \mathrm{~L} / \mathrm{min}$. For operations in MS/MS mode, helium was used as collision gas was with a pressure of $4 \times 10^{-4}$ milli bar. A capillary voltage of $3.5 \mathrm{kV}$ was used in positive ionization mode. The interface temperature was set to 360 ${ }^{\circ} \mathrm{C}$. The scan range was $50-450 \mathrm{~m} / \mathrm{Z}$. Agilent $1200 \mathrm{HPLC}$ system with Xterra MS C18 column ( $5 \mu \mathrm{m}$ particle size, 4.6 $\mathrm{mm}$ i.d. x $150 \mathrm{~mm}$ length), gradient elution of $0.4 \mathrm{ml}$ per minute having $0.1 \%$ formic acid in acetonitrile as mobile phase $\mathrm{A}$ and $0.1 \%$ formic acid in milli $\mathrm{q}$ water as mobile phase $\mathrm{B}$, the flow programmed from $5 \%$ to $95 \%$ of mobile phase A were used for the separation of spirotetramat, metabolite enol and imidacloprid. The injection volume used for the analysis was $10 \mu 1$.

\section{Preparation of Zinc Oxide Nanorods}

The Zinc oxide nanorods are prepared using the method described [23]. The process involves the ultrasonic irradiation of $50 \mathrm{~mL}$ of aqueous solution containing $0.05 \mathrm{M}$ of zinc acetate and $0.05 \mathrm{M}$ of triethanolamine, at $80^{\circ} \mathrm{C}$ for two hours. The resulting product was washed several times with de-ionized water followed by methanol. Filtered and dried at $200^{\circ} \mathrm{C}$ in air for 2 hours. The structural morphology of the particle was done by scanning electron microscope and presented in Fig. (1). The particles are found to be rod shaped with 100 to $250 \mathrm{~nm}$ dia and 1 to $2 \mu \mathrm{m}$ length.

\section{Photocatalysis}

The photocatalysis of spirotetramat and imidacloprid insecticides in water was studied by spiking two different concentrations of combinational insecticide formulation (480 SC) containing spirotetramat $12 \%$ and imidacloprid $36 \%$ at 1.0 and $2.0 \mathrm{mg} / \mathrm{L}$ of the product. The study was conducted in Milli q water and in three different buffers of $\mathrm{pH} 4.0,7.0$ and 9.0. Three replicate spiking solutions were prepared at each fortification level along with control samples for comparison. Two sets of spiked concentrations are prepared for the studies. To one set of samples the catalyst (Zinc oxide nanorods) was added and the other set was studied without the addition of catalyst. Exposed all the samples under direct sunlight every day for a period of 11 hours and monitored the catalytic activity by collecting and analysing the aliquots of the water sample on different predetermined intervals. The day temperature of the water samples during the period varied between 27 to $44{ }^{\circ} \mathrm{C}$. The intensity of the sunlight light was measured during the exposure. This was presented graphically in Fig. (2). On each sampling occasion, filtered aliquot of the collected sample using $0.2 \mu$ membrane filter and collected the filtrates in to amber coloured vials. All the samples were stored in dark at $<4^{\circ} \mathrm{C}$ before subjecting to HPLC analysis. The samples fortified with Zinc oxide were

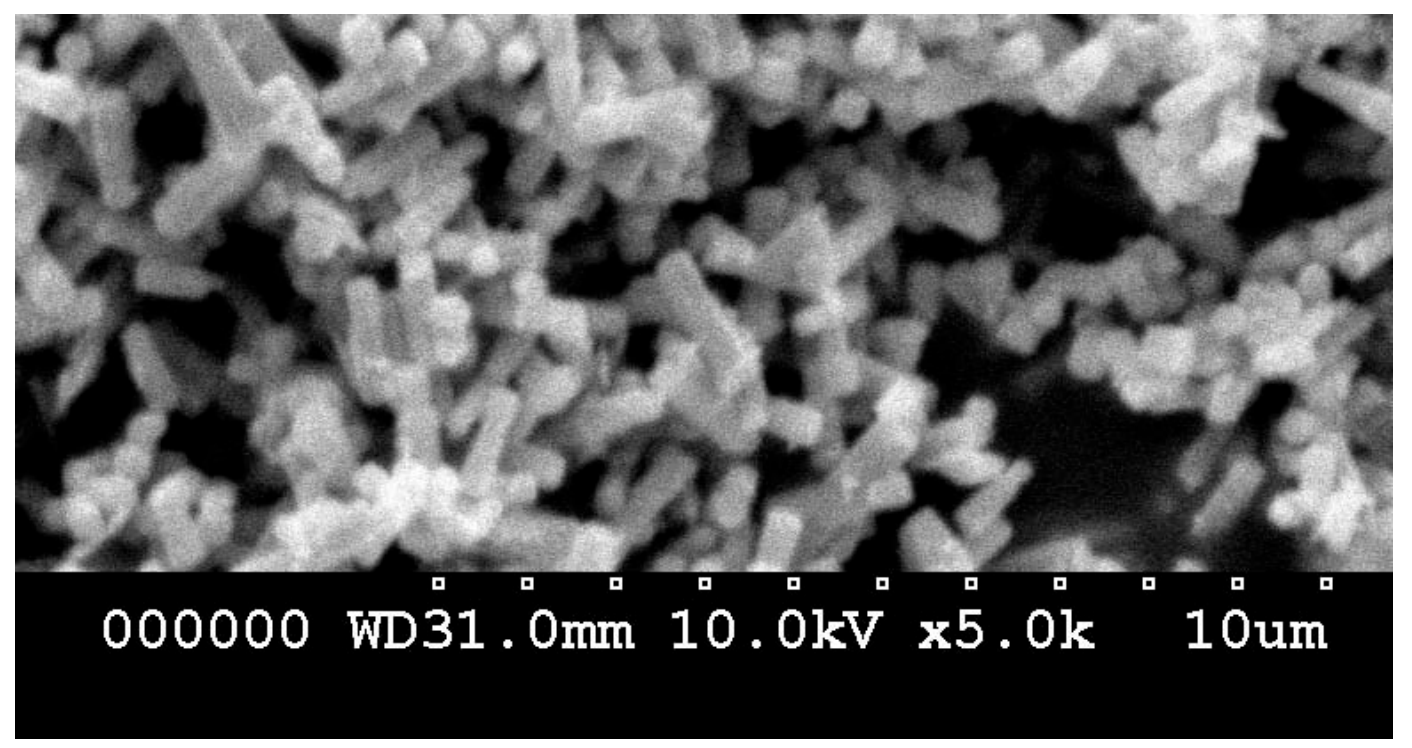

Fig. (1). Scanning Electron Microscope Image of Zinc oxide nano rods (100-250 nm). 


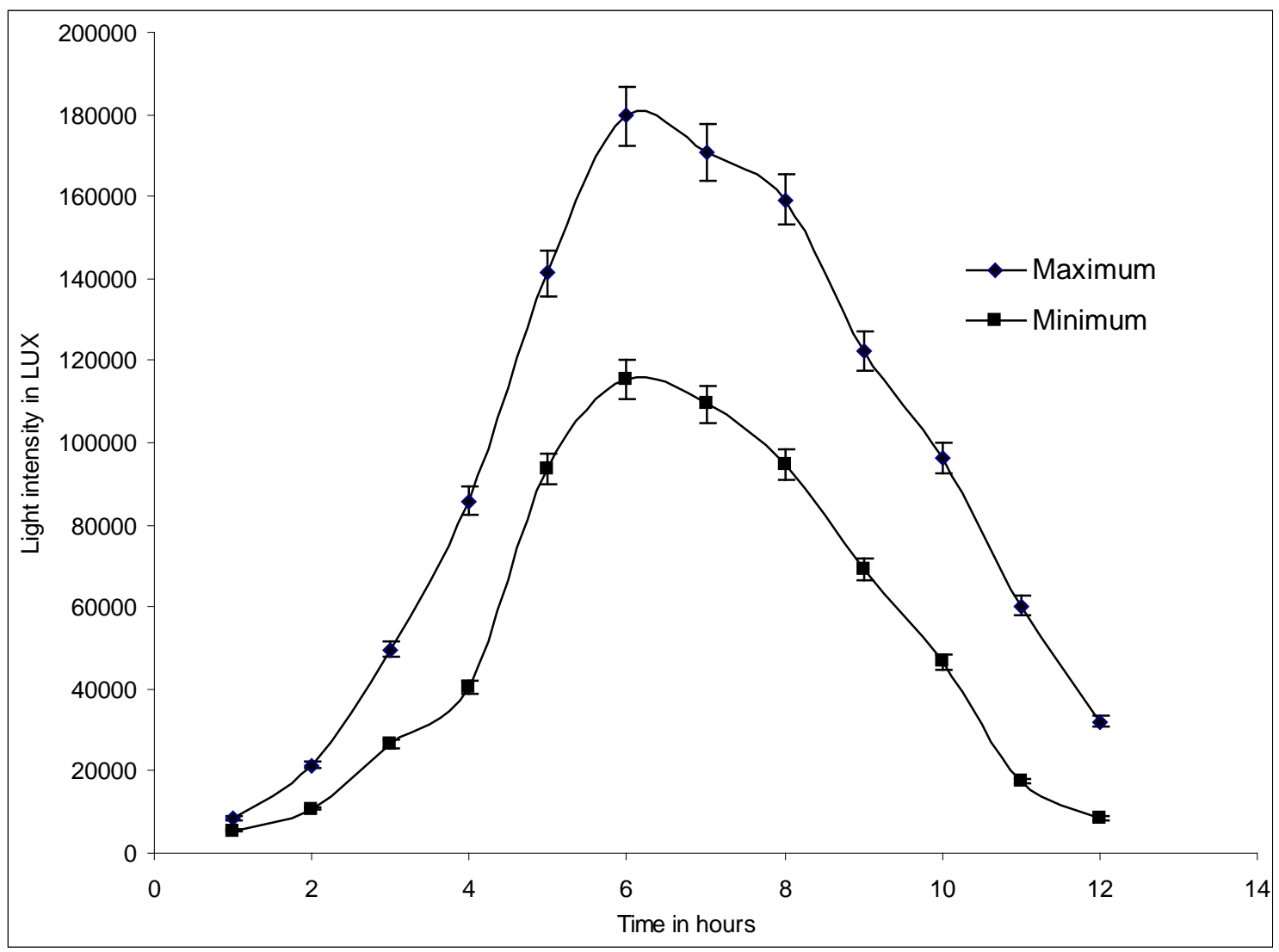

Fig. (2). Intensity of light during the study period.

centrifuged using Beckman cooling centrifuge at 10000 rotations per minute for 3 minutes at $2^{\circ} \mathrm{C}$. Transferred the supernent and stored in dark at $<4^{\circ} \mathrm{C}$ until analysis to avoid further degradation of residues.

The effect of adsorption of insecticides $0.1 \mathrm{mg} / \mathrm{L}$ on the catalyst was checked by the addition $0.07 \mathrm{~g} / \mathrm{L}$ of catalyst in water. The sample was kept stirring continuously for a period of 3 hours in dark without aeration. The water samples in duplicate were collected every hour during this time period and analysed for the residues.

\section{Recovery and Limit of Detection}

Recovery studies were conducted by fortifying two different concentrations of spirotetramat and imidacloprid $(0.2$ $0.02 \mathrm{mg} / \mathrm{L}$ ). The limit of quantification (LOQ) was established based on the recovery study and signal to noise ratio with minimum of 10:1. The linearity of the method was studied over the concentration range $5.0-0.01 \mathrm{mg} / \mathrm{L}$ by using HPLC-UV method.

\section{Confirmation of Residues by LC-ESI-MS/MS}

The samples were analyzed by LC-ESI-MS/MS detection. A high capacity ion trap MS/MS with dioctapole was used for the confirmation of residues in electro spray ionization mode. The insecticide imidacloprid got eluted at 8.0 minute and showed a molecular ion peak at $\mathrm{m} / \mathrm{Z} 256.2$ and the fragment ions appeared at 208.6; 174.6; 127.6. The spirotetramat and its metabolite enol are eluted at 11.1 and 9.2 minutes respectively. Spirotetramat showed a molecular ion peak at $\mathrm{m} / \mathrm{Z}$ 374.2 and the prominent fragment ions at $\mathrm{m} / \mathrm{Z} 329.9 ; 301.9$;
269.8; 252.7 and 215.7. The metabolite enol has the molecular ion peak at $\mathrm{m} / \mathrm{Z} 302$ and the fragment ion peaks at $\mathrm{m} / \mathrm{Z} 269.8$; $252.7 ; 215.7$. The method has the limit of quantification 0.1 $\mu \mathrm{g} / \mathrm{L}$. The complete mineralization of residues was confirmed by analysing the sample by LC-ESI-MS/MS.

\section{RESULTS AND DISCUSSION}

The photolysis data of imidacloprid and spirotetramat insecticide in aqueous media at different $\mathrm{pH}$ levels under the influence of direct sun light without the catalyst was presented in Tables $\mathbf{1}$ and $\mathbf{2}$. The study showed that the compounds degraded to below detectable levels with in 20 days in milli q water. In acidic water ( $\mathrm{pH} 4.0)$ and in neutral water $(\mathrm{pH} 7.0)$ the degradation was within 10 days. Degradation of imidacloprid is further rapid in basic water $(\mathrm{pH} 9.0)$ and the residues went down the detectable level within 7 days. The spirotetramat residue was rapidly degraded with in 5 hours in basic water.

\section{Adsorption of Insecticides on the Catalyst}

The adsorption of insecticides on the catalyst was tested by quantifying the presence of residues in water hourly in sequence after the addition of catalyst. The results showed no significant adsorption of residues by zinc oxide nanorods when tested for a period of three hours with constant stirring in dark. Recovery studies in water and different buffers were conducted with $0.07 \mathrm{~g} / \mathrm{L}$ level of zinc oxide catalyst in dark. The recovery in Milli q water was found to be in the range 88 to $94 \%$ for spirotetramat, 88 to $96 \%$ for metabolite enol and 89 to $93 \%$ for imidacloprid. Recovery in acidic water 
Table 1. Photolysis of Imidacloprid and Spirotetramat Under Direct Sun Light in Milli q, Acidic and Neutral Water (without Catalyst)

\begin{tabular}{|c|c|c|c|c|}
\hline \multirow{2}{*}{ Tested Dose } & \multicolumn{2}{|c|}{ Imidacloprid } & \multicolumn{2}{|c|}{ Spirotetramat } \\
\hline & $0.36 \mathrm{mg} / \mathrm{L}$ & $0.72 \mathrm{mg} / \mathrm{L}$ & $0.12 \mathrm{mg} / \mathrm{L}$ & $0.24 \mathrm{mg} / \mathrm{L}$ \\
\hline $\begin{array}{c}\text { Sampling Occasions } \\
\text { Days }\end{array}$ & \multicolumn{4}{|c|}{$\begin{array}{l}\text { Dissipation of Residues in } \\
\text { Milli Q Water (mg/L) }\end{array}$} \\
\hline 0 & 0.32 & 0.62 & 0.12 & 0.24 \\
\hline 1 & 0.3 & 0.61 & 0.1 & 0.21 \\
\hline 3 & 0.26 & 0.54 & 0.08 & 0.19 \\
\hline 5 & 0.19 & 0.44 & 0.05 & 0.14 \\
\hline 7 & 0.14 & 0.31 & 0.03 & 0.1 \\
\hline 10 & 0.09 & 0.19 & $<\mathrm{LOQ}$ & 0.05 \\
\hline 15 & 0.04 & 0.08 & $<\mathrm{LOQ}$ & $<\mathrm{LOQ}$ \\
\hline 20 & $<\mathrm{LOQ}$ & $<\mathrm{LOQ}$ & $<\mathrm{LOQ}$ & $<\mathrm{LOQ}$ \\
\hline \multicolumn{5}{|c|}{ Dissipation of Residues in Acidic Water (mg/L) } \\
\hline 0 & 0.33 & 0.69 & 0.13 & 0.24 \\
\hline 1 & 0.31 & 0.63 & 0.11 & 0.22 \\
\hline 3 & 0.3 & 0.58 & 0.1 & 0.21 \\
\hline 5 & 0.23 & 0.49 & 0.07 & 0.16 \\
\hline 7 & 0.17 & 0.36 & 0.06 & 0.12 \\
\hline 10 & 0.12 & 0.24 & 0.03 & 0.06 \\
\hline 15 & 0.05 & 0.11 & $<\mathrm{LOQ}$ & $<\mathrm{LOQ}$ \\
\hline 20 & $<\mathrm{LOQ}$ & $<\mathrm{LOQ}$ & $<\mathrm{LOQ}$ & $<\mathrm{LOQ}$ \\
\hline \multicolumn{5}{|c|}{ Dissipation of Residues in Neutral Water (mg/L) } \\
\hline 0 & 0.13 & 0.24 & 0.35 & 0.7 \\
\hline 1 & 0.12 & 0.22 & 0.31 & 0.62 \\
\hline 3 & 0.05 & 0.1 & 0.11 & 0.17 \\
\hline 5 & $<\mathrm{LOQ}$ & $<\mathrm{LOQ}$ & 0.08 & 0.12 \\
\hline 7 & $<\mathrm{LOQ}$ & $<\mathrm{LOQ}$ & $<\mathrm{LOQ}$ & 0.04 \\
\hline 10 & $<\mathrm{LOQ}$ & $<\mathrm{LOQ}$ & $<\mathrm{LOQ}$ & $<\mathrm{LOQ}$ \\
\hline
\end{tabular}

was between 89 to $92 \%$ for spirotetramat, 94 to $98 \%$ for enol and 92 to $95 \%$ for imidacloprid. The recovery percentage in neutral water was 85 to $92 \%, 89$ to $93 \%, 86$ to $94 \%$ for spirotetramat, metabolite enol and imidacloprid respectively. The recovery percentage for spirotetramat, enol and imidacloprid are 83 to $93 \%$, and 89 to $97 \%$ respectively in basic water.

\section{Influence of Catalyst and the pH of the Buffer Solutions}

To identify the nominal concentration of catalyst required for the rapid degradation of the insecticides the amount of zinc oxide nanorods added to the aqueous solution was varied from $0.02 \mathrm{~g}$ to $0.2 \mathrm{~g} / \mathrm{L}$ level. The increase in amount of catalyst enhanced the degradation and attained equilibrium at a concentration level $0.07 \mathrm{~g} / \mathrm{L}$. The dissipation of the
Table 2. Photolysis of Imidacloprid and Spirotetramat Under Direct Sun Light in Basic Water

\begin{tabular}{|c|c|c|}
\hline \multirow{2}{*}{ Dissipation of Residues in Basic Water $(\mathbf{m g} / \mathbf{L})$} \\
\hline \multirow{2}{*}{ Occasion in Hours } & \multicolumn{2}{|c|}{ Spirotetramat } \\
\cline { 2 - 3 } & $\mathbf{0 . 1 2} \mathbf{~ m g / L}$ & $\mathbf{0 . 2 4} \mathbf{~ m g / L}$ \\
\hline \hline 0 & 0.13 & 0.23 \\
\hline 0.5 & 0.1 & 0.21 \\
\hline 1 & 0.08 & 0.19 \\
\hline 3 & 0.04 & 0.09 \\
\hline 5 & $<$ LOQ & $<\mathrm{LOQ}$ \\
\hline \multirow{2}{*}{ Occasion in Days } & & $\mathbf{I m i d a c l o p r i d}$ \\
\cline { 2 - 3 } & $\mathbf{0 . 3 6} \mathbf{~ m g} / \mathbf{L}$ & $\mathbf{0 . 7 2} \mathbf{~ m g} / \mathbf{L}$ \\
\hline \hline 0 & 0.34 & 0.71 \\
\hline 1 & 0.2 & 0.42 \\
\hline 3 & 0.11 & 0.2 \\
\hline 5 & $<$ LOQ & $<\mathrm{LOQ}$ \\
\hline
\end{tabular}

compound was found rapid at this level under the influence of zinc oxide catalyst. Further experiments were conducted at this concentration level. The photocatalysis of insecticides in presence of zinc oxide nanorods under the influence of direct sun light and different buffer solutions were presented in Table 3.

The DT 50 and DT 90 values calculated from the dissipation data of insecticides are presented in Table 4. From the study it was observed that the reaction process was influenced by the changes in $\mathrm{pH}$. With lower $\mathrm{pH}$, the reaction observed is slow and with increase in $\mathrm{pH}$ the dissipation is rapid. When compared with imidaclorid the dissipation of spirotetramat is more rapid in basic solution. Further it was observed that the aeration of solutions after the addition of Zinc oxide nano catalyst enhanced the degradation of insecticide in water. The influence of the aeration in decontamination of residues in water was presented in Fig. (3).

The rate constant $\mathrm{k}$ [24] was calculated from the dissipation of imidacloprid and spirotetramat with time using the following equation

$\mathrm{K}=\ln \mathrm{C}_{1} / \mathrm{C}_{2} / \Delta \mathrm{t}$

where $\Delta t$ is the time interval between $t_{1}$ and $t_{2}$ and $C_{1}, C_{2}$ are the concentration of pesticides at times $t_{1}$ and $t_{2}$ respectively. The higher coefficient of correlation $\left(R^{2}=1.000\right)$ for the least square indicates that the first order kinetics in dissipation of both the insecticides in water. The rate constant $\mathrm{k}$ was calculated from the first order rate equation and summarised in Table 5.

The rate constant of imidacloprid in direct photolysis reaction (without the catalyst) at the studied concentrations $(0.36$ and $0.72 \mathrm{mg} / \mathrm{L})$ are $0.025,0.035$ in milli $\mathrm{q}$ water; 
Table 3. Photocatalysis of Imidacloprid and Spirotetramat Under Direct Sun Light in Presence of Zinc Oxide Nanorods as Catalyst - Dissipation in Water at Different pH Levels

\begin{tabular}{|c|c|c|c|c|c|c|c|c|c|}
\hline \multirow{2}{*}{$\begin{array}{l}\text { Tested } \\
\text { Dose }\end{array}$} & \multicolumn{2}{|c|}{ Imidacloprid } & \multicolumn{2}{|c|}{ Spirotetramat } & \multirow{2}{*}{$\begin{array}{l}\text { Tested } \\
\text { Dose }\end{array}$} & \multicolumn{2}{|c|}{ Imidacloprid } & \multicolumn{2}{|c|}{ Spirotetramat } \\
\hline & $0.36 \mathrm{mg} / \mathrm{L}$ & $0.72 \mathrm{mg} / \mathrm{L}$ & $0.12 \mathrm{mg} / \mathrm{L}$ & $0.24 \mathrm{mg} / \mathrm{L}$ & & $0.36 \mathrm{mg} / \mathrm{L}$ & $0.72 \mathrm{mg} / \mathrm{L}$ & $0.12 \mathrm{mg} / \mathrm{L}$ & $0.24 \mathrm{mg} / \mathrm{L}$ \\
\hline $\begin{array}{c}\text { Sampling } \\
\text { Occasions } \\
\text { (Hours) }\end{array}$ & \multicolumn{4}{|c|}{ Residues in Milli Q Water $(\mathrm{mg} / \mathrm{L})$} & $\begin{array}{c}\text { Sampling } \\
\text { Occasions } \\
\text { (Hours) }\end{array}$ & \multicolumn{4}{|c|}{ Residues in Neutral Water $(\mathrm{mg} / \mathrm{L})$} \\
\hline 0 & 0.31 & 0.59 & 0.13 & 0.25 & 0 & 0.27 & 0.56 & 0.13 & 0.23 \\
\hline 1 & 0.29 & 0.57 & 0.11 & 0.21 & 1 & 0.25 & 0.52 & 0.1 & 0.2 \\
\hline 3 & 0.26 & 0.53 & 0.09 & 0.17 & 3 & 0.23 & 0.47 & 0.08 & 0.17 \\
\hline 5 & 0.22 & 0.46 & 0.07 & 0.15 & 5 & 0.2 & 0.39 & 0.05 & 0.12 \\
\hline 7 & 0.18 & 0.37 & 0.05 & 0.09 & 7 & 0.16 & 0.3 & 0.03 & 0.08 \\
\hline 10 & 0.14 & 0.24 & 0.03 & 0.06 & 10 & 0.12 & 0.25 & $<$ LOQ & 0.04 \\
\hline 20 & 0.08 & 0.17 & $<\mathrm{LOQ}$ & $<\mathrm{LOQ}$ & 20 & 0.06 & 0.14 & $<$ LOQ & $<$ LOQ \\
\hline 30 & 0.03 & 0.08 & $<\mathrm{LOQ}$ & $<\mathrm{LOQ}$ & 30 & $<\mathrm{LOQ}$ & 0.06 & $<\mathrm{LOQ}$ & $<$ LOQ \\
\hline 60 & $<\mathrm{LOQ}$ & $<\mathrm{LOQ}$ & $<\mathrm{LOQ}$ & $<\mathrm{LOQ}$ & 60 & $<\mathrm{LOQ}$ & $<\mathrm{LOQ}$ & $<\mathrm{LOQ}$ & $<$ LOQ \\
\hline \multicolumn{5}{|c|}{ Residues in Acidic Water (mg/L) } & \multicolumn{5}{|c|}{ Residues in Basic Water (mg/L) } \\
\hline 0 & 0.29 & 0.59 & 0.12 & 0.25 & 0 & 0.26 & 0.53 & 0.11 & 0.24 \\
\hline 1 & 0.28 & 0.57 & 0.1 & 0.23 & 0.5 & 0.24 & 0.51 & 0.08 & 0.13 \\
\hline 3 & 0.26 & 0.54 & 0.08 & 0.2 & 1 & 0.23 & 0.48 & 0.03 & 0.06 \\
\hline 5 & 0.23 & 0.45 & 0.06 & 0.18 & 2 & 0.21 & 0.42 & $<\mathrm{LOQ}$ & $<\mathrm{LOQ}$ \\
\hline 7 & 0.19 & 0.38 & 0.03 & 0.14 & 3 & 0.18 & 0.38 & $<\mathrm{LOQ}$ & $<\mathrm{LOQ}$ \\
\hline 10 & 0.16 & 0.29 & $<\mathrm{LOQ}$ & 0.1 & 5 & 0.16 & 0.3 & $<\mathrm{LOQ}$ & $<\mathrm{LOQ}$ \\
\hline 20 & 0.09 & 0.19 & $<\mathrm{LOQ}$ & $<\mathrm{LOQ}$ & 7 & 0.09 & 0.23 & $<\mathrm{LOQ}$ & $<\mathrm{LOQ}$ \\
\hline 30 & 0.03 & 0.09 & $<\mathrm{LOQ}$ & $<\mathrm{LOQ}$ & 10 & 0.03 & 0.14 & $<\mathrm{LOQ}$ & $<\mathrm{LOQ}$ \\
\hline 60 & $<\mathrm{LOQ}$ & $<\mathrm{LOQ}$ & $<\mathrm{LOQ}$ & $<\mathrm{LOQ}$ & 15 & $<\mathrm{LOQ}$ & $<\mathrm{LOQ}$ & $<\mathrm{LOQ}$ & $<\mathrm{LOQ}$ \\
\hline
\end{tabular}

Table 4. DT 50 and DT 90 Value of Imidacloprid and Spirotetramat in Water at Different pH Conditions with and without Zinc Oxide Nano Catalyst

\begin{tabular}{|c|c|c|c|c|c|c|c|c|}
\hline \multirow{3}{*}{ Insecticide } & \multicolumn{8}{|c|}{ DT 50 and DT 90 in Days (Without Catalyst) } \\
\hline & \multicolumn{2}{|c|}{ Milli Q Water } & \multicolumn{2}{|c|}{ pH 4.0 } & \multicolumn{2}{|c|}{ pH 7.0 } & \multicolumn{2}{|c|}{ pH 9.0 } \\
\hline & DT 50 & DT 90 & DT 50 & DT 90 & DT 50 & DT 90 & DT 50 & DT 90 \\
\hline Imidacloprid & $4.9 \pm 0.1$ & $16.3 \pm 0.2$ & $5.6 \pm 0.2$ & $18.5 \pm 0.4$ & $2.2 \pm 0.2$ & $7.2 \pm 0.3$ & $1.8 \pm 0.1$ & $6.0 \pm 0.3$ \\
\hline \multirow[t]{2}{*}{ Spirotetramat } & $4.6 \pm 0.1$ & $15.3 \pm 0.2$ & $6.1 \pm 0.2$ & $20.4 \pm 0.6$ & $2.3 \pm 0.2$ & $7.5 \pm 0.3$ & $1.9 \pm 0.2^{*}$ & $6.6 \pm 0.6^{*}$ \\
\hline & \multicolumn{8}{|c|}{ With Zinc Oxide nano catalyst @ $0.07 \mathrm{~g} / \mathrm{L}$} \\
\hline Imidacloprid & $10.1 \pm 0.2$ & $33.5 \pm 0.5$ & $11.5 \pm 0.1$ & $38.3 \pm 0.5$ & $9.2 \pm 0.2$ & $30.5 \pm 0.7$ & $4.0 \pm 0.2$ & $16.4 \pm 0.3$ \\
\hline Spirotetramat & $5.0 \pm 0.2$ & $16.7 \pm 0.6$ & $5.5 \pm 0.5$ & $19.4 \pm 0.7$ & $3.7 \pm 0.3$ & $12.1 \pm 0.7$ & $0.5 \pm 0.1$ & $1.7 \pm 0.2$ \\
\hline
\end{tabular}

* DT 50 and DT 90 value in hours.

$0.024,0.033$ in acidic water, 0.056, 0.057 in neutral water and 0.021 in basic water sample. The rate constant values increased significantly with the addition of catalyst. The rate constant values calculated for imidacloprid in presence of catalyst are $0.54,0.68$ in milli q water and in acidified water sample, 0.53 , 0.62 in neutral water and $0.68,0.8$ in basic water. 


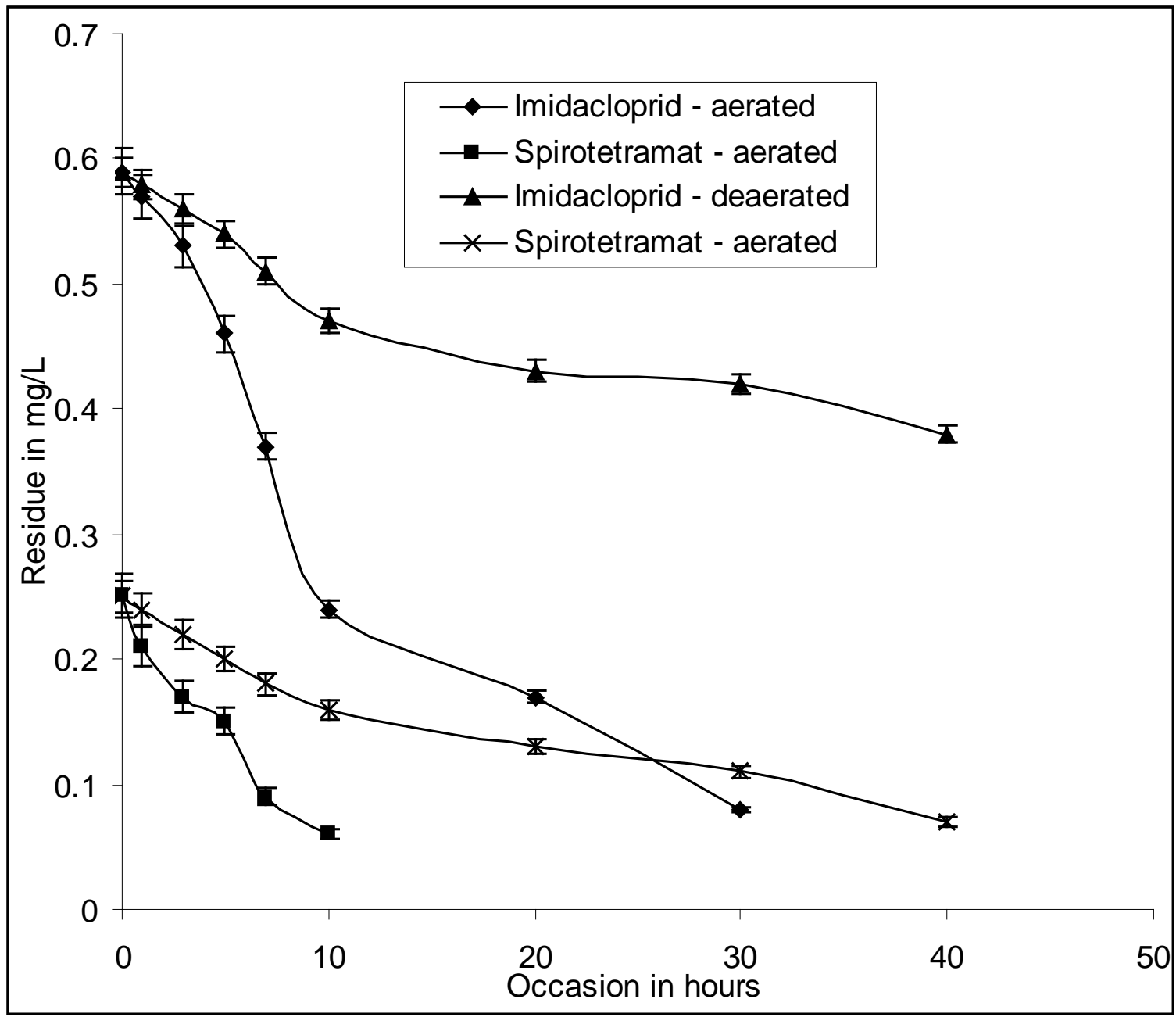

Fig. (3). Influence of aeration in degradation of residues in water.

Table 5. Rate Constant of Imidacloprid and Spirotetramat in Water at Different pH Conditions with and without Zinc Oxide Nano Catalyst

\begin{tabular}{|c|c|c|c|c|c|c|}
\hline \multirow{3}{*}{ Dosage in $\mathbf{m g} / \mathrm{L}$} & \multirow{3}{*}{ Substrate } & \multicolumn{5}{|c|}{ Rate constant } \\
\hline & & \multicolumn{2}{|c|}{ Spirotetramat } & \multirow{2}{*}{ Dosage in $\mathrm{mg} / \mathrm{L}$} & \multicolumn{2}{|c|}{ Imidacloprid } \\
\hline & & Without Catalyst & With Catalyst & & Without Catalyst & With Catalyst \\
\hline 0.12 & \multirow{2}{*}{ Milli Q water } & 0.024 & 0.5 & 0.36 & 0.025 & 0.54 \\
\hline 0.24 & & 0.008 & 0.17 & 0.72 & 0.035 & 0.54 \\
\hline 0.12 & \multirow{2}{*}{$\mathrm{pH}$ 4.0 Buffer } & 0.022 & 0.59 & 0.36 & 0.024 & 0.68 \\
\hline 0.24 & & 0.009 & 0.21 & 0.72 & 0.033 & 0.68 \\
\hline 0.12 & \multirow{2}{*}{$\mathrm{pH} 7.0$ buffer } & 0.062 & 0.48 & 0.36 & 0.056 & 0.53 \\
\hline 0.24 & & 0.053 & 0.54 & 0.72 & 0.057 & 0.62 \\
\hline 0.12 & \multirow{2}{*}{ pH 9.0 buffer } & 1.337 & 1.46 & 0.36 & 0.021 & 0.68 \\
\hline 0.24 & & 0.699 & 0.77 & 0.72 & 0.021 & 0.8 \\
\hline
\end{tabular}

The rate constant values calculated for spirotetramat under the influence of direct sun light (without the catalyst) are; milli q water - 0.024, 0.008; acidic water - 0.022, 0.009; neutral water $-0.062,0.053$ and basic water $1.337,0.699$ at the tested concentrations 0.12 and $0.24 \mathrm{mg} / \mathrm{L}$ respectively. The rate constant values of photocatlytic reaction in presence of catalyst are; milli q water - $0.50,0.17$; acidic water - 0.59 , 0.21 ; neutral water $-0.48,0.54$ and basic water $-1.46,0.77$. This clearly indicates that zinc oxide nano rods enhanced the photocatalytic degradation of imidacloprid and spirotetramat. 
During the photolysis study, formation of metabolite of spirotetramat (enol form) was identified by HPLC-MS-MS detection. In the catalytic reaction of the metabolite enol formation was observed within three hours after the application and the residues are at $0.03 \mathrm{mg} / \mathrm{L}$. The fifth hour sample showed $0.06 \mathrm{mg} / \mathrm{L}$ (milli $\mathrm{q}$ water) and $0.07 \mathrm{mg} / \mathrm{L}$ (acidic water and neutral water). The levels of residues of metabolite were $0.05 \mathrm{mg} / \mathrm{L}$ in milli q water, $0.06 \mathrm{mg} / \mathrm{L}$ in acidic water and neutral water on $7^{\text {th }}$ hour. Residues degraded to 0.03 $\mathrm{mg} / \mathrm{L}$ by $20^{\text {th }}$ hour. Complete dissipation of residues was observed by $30^{\text {th }}$ hour. The basic water showed 0.03 to 0.04 $\mathrm{mg} / \mathrm{L}$ metabolite 30 minutes after starting experiment probably due to the rapid hydrolysis of spirotetramat. The metabolite reached maximum concentration $0.07 \mathrm{mg} / \mathrm{L}$ by second hours and subsequently degraded to $0.04 \mathrm{mg} / \mathrm{L}$ level by $20^{\text {th }}$ hour and $0.03 \mathrm{mg} / \mathrm{L}$ level by $30^{\text {th }}$ hour. Complete dissipation of the metabolite was observed by $40^{\text {th }}$ hour. The formation of metabolite and residues of parent molecules are confirmed by LC-ESI-MS/MS. The total ion chromatogram for the residues in standard, on $3^{\text {rd }}$ day sample and after complete mineralization of the residues in water samples are presented in Fig. (4), observed that the presence of metabolite enol on the third day sample. Further the residues were degraded to below detectable level in presence of zinc oxide catalyst. The confirmation spectra for residues and metabolite and its fragmentation patterns are presented in Fig. (5).

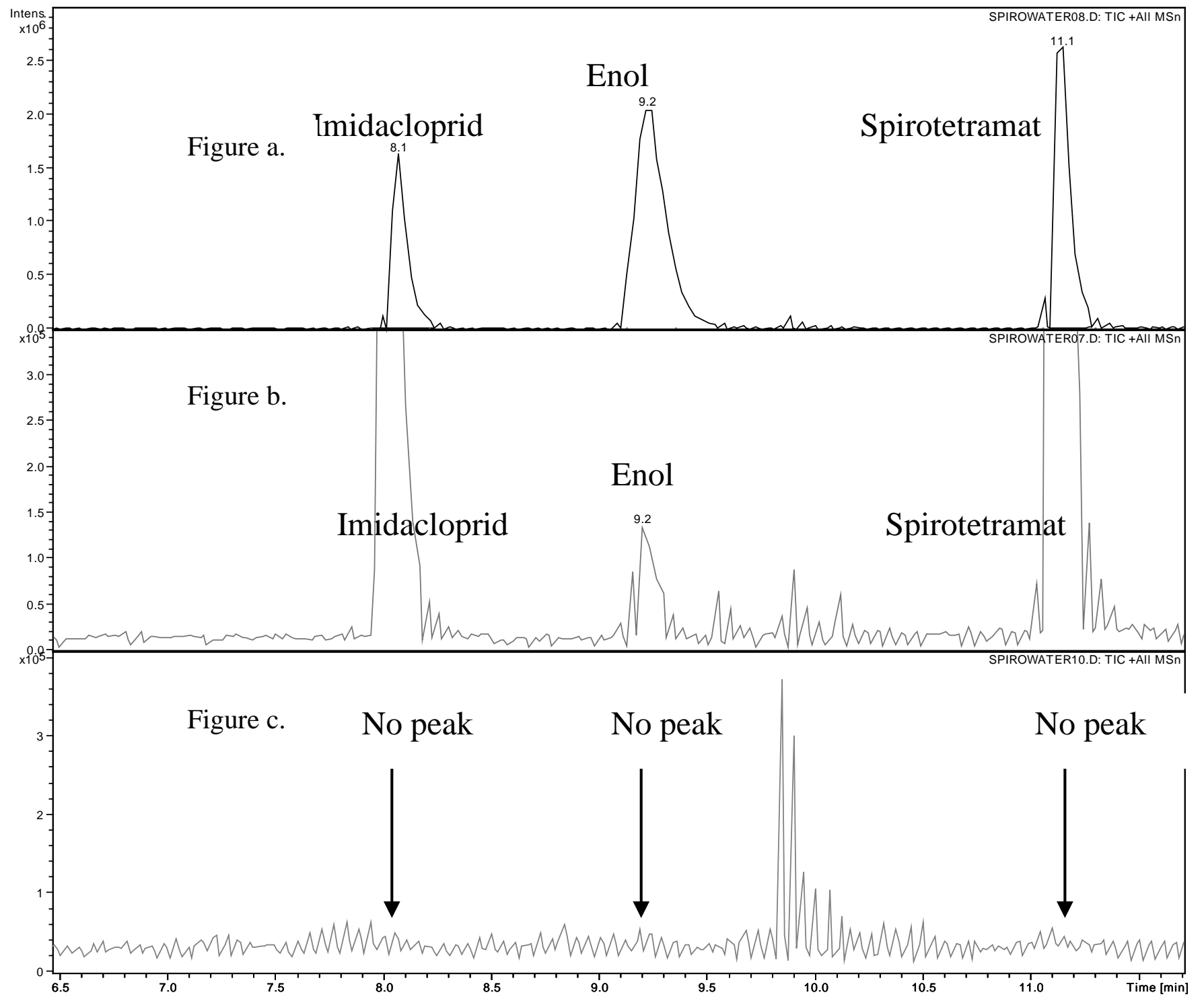

a. Standard mixture containing imidacloprid, spirotetramat and enol at $0.1 \mathrm{mg} / \mathrm{L}$

b. Third hour sample showing the formation of metabolite in milli q water sample

c. Milli q water sample after complete degradation of residues

Fig. (4). Electrospray tandem mass spectrometry - Total ion chromatogram of standard and sample. 


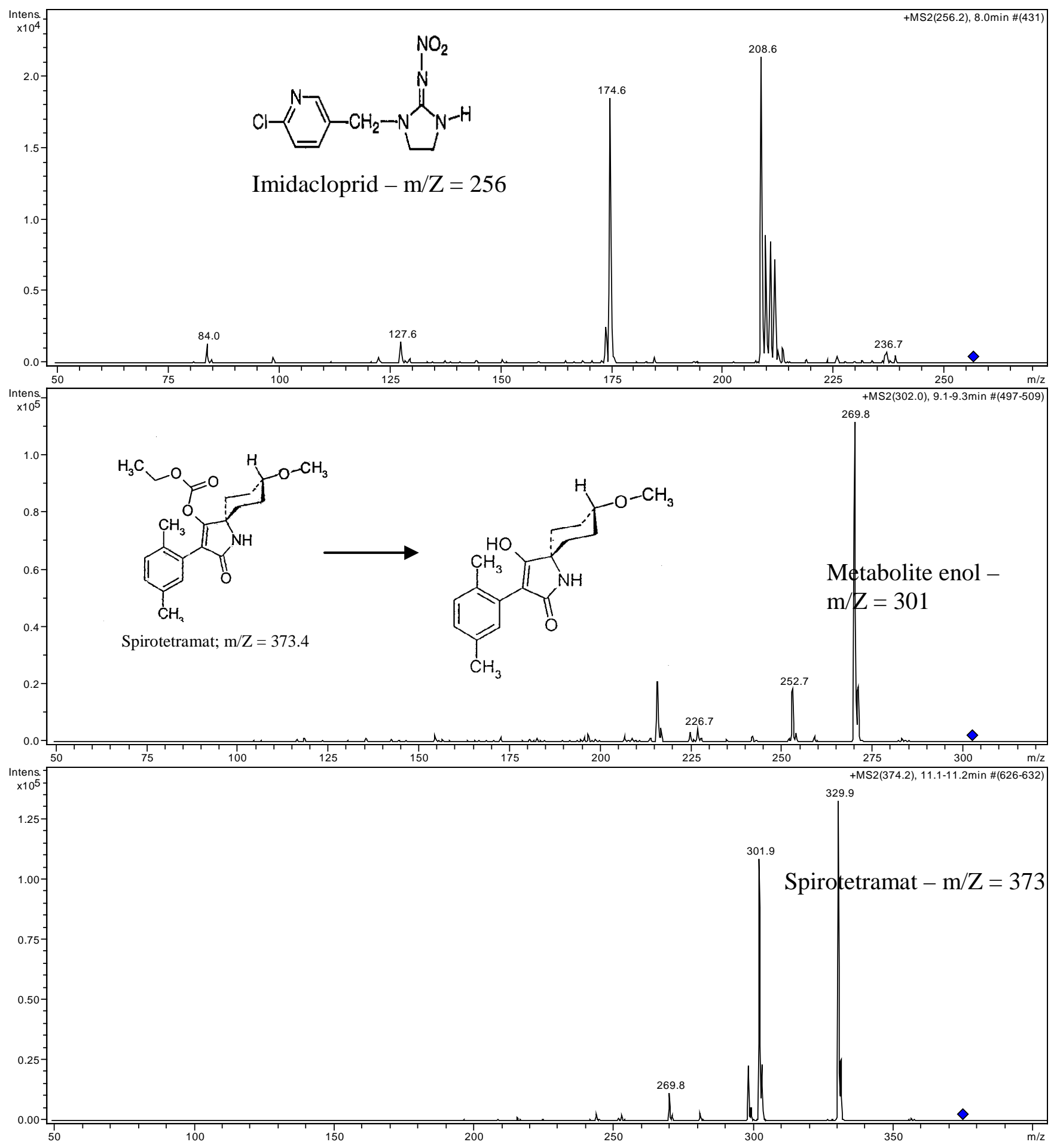

Fig. (5). Mass spectra of imidacloprid, metabolite enol and spirotetramat by LC-ESI-MS/MS.

\section{CONCLUSIONS}

The photocatalytic degradation of residues of spirotetramat and imidacloprid clearly indicates that the sunlight photolysis was influenced by the addition of the zinc oxide nanorods as catalysts. The catalysis reaction proceeded rapidly degrading the molecules very fast. This was further enhanced with the increase in $\mathrm{pH}$ of the aqueous solutions. The basic $\mathrm{pH}$ contributed significantly degrading the residues very rapidly. Metabolites of spirotetramat (enol form) was identified and quantified by LC-ESI-MS/MS detection. The commercially available zinc oxide was also tried by several researchers in decontamination process.

Few pesticides such as 2, 4-D and Monocrotophos are tried for this purpose. However when compared the present findings with the published data it is very clear that the zinc oxide nano rods functions as a more effective catalyst in the 
decontamination process. Thus the greater photocatalytic activity of zinc oxide nano rods can be attributed due to their well defined nano particles size facilitating the easy transformation of energy.

\section{ACKNOWLEDGEMENTS}

The authors thanks the Bayer crop Science Limited, India, for providing the analytical standards and the formulation. We also thank the management and Director, IIBAT, Dr. P. Balakrishnamurthy for providing necessary facility.

\section{REFERENCES}

[1] Ayman, D.; Amjad, S.; Sameer, A.; Ramzi, S.; Jack, CN. Imidacloprid residues in fruits, vegetables and water samples from Palestine. Environ. Geochem. Health, 2007, 29, 45-50.

[2] Malato, S.; Blanco, J.; Vidal, A.; Alarcón, D.; Maldonado, MI.; Cáceres, J.; Gernjak, W. Applied studies in solar photocatalytic detoxification: an overview. Solar Energy, 2003, 75, 329-36.

[3] Malato, S.; Blanco, J.; Cáceres, J.; Fernández-Alba AR.; Agüera, A.; Rodríguez, A.; Photocatalytic treatment of water-soluble pesticides by photo-Fenton and $\mathrm{TiO}_{2}$ using solar energy. Catal. Today, 2002, 76, 209-20.

[4] Moza, PN.; Hustert, K.; Feicht, E.; Kettrup, A. Photolysis of imidacloprid in aqueous solution. Chemosphere, 1998, 36, 497-502.

[5] Malato, S.; Caceres, J.; Agüera, A.; Mezcua, M.; Hernando, D.; Vial, J.; Fernández-Alba AR. Degradation of imidacloprid in water by photo-Fenton and $\mathrm{TiO}_{2}$ photocatalysis at a solar pilot plant: a comparative study. Environ. Sci. Technol., 2001, 35, 4359-66.

[6] Phanikrishna Sharma, MV.; Durga Kumari, V.; Subrahmanyam, M. $\mathrm{TiO}_{2}$ supported over SBA-15: An efficient photocatalyst for the pesticide degradation using solar light. Chemosphere, 2008, 73, 1562-69.

[7] Kitsiou, V.; Filippidis, N.; Mantzavinos, D.; Poulios, I. Heterogeneous and homogeneous photocatalytic degradation of the insecticide imidacloprid in aqueous solutions. Appl. Catalysis B: Environ., In Press.

[8] Mahmoodi, NM.; Mokhtar, A.; Nargess, YL.; Kamaladin, G. Photocatalytic degradation of agricultural $\mathrm{N}$-heterocyclic organic pollutants using immobilized nanoparticles of titania. J. Hazard. Mater., 2007, 145, 65-71.

[9] Sandhya, R.; Suja, D.; Suguna, Y. Photocatalytic degradation of phosphamidon on semiconductor oxides. J. Hazard. Mater., 2003, 102, 217-29.

[10] Černigoj, U.; Štangar, U.L.; Trebše, P. Degradation of neonicotinoid insecticides by different advanced oxidation processes and studying the effect of ozone on $\mathrm{TiO}_{2}$ photocatalysis. Appl. Catalysis B: Environ., 2007, 75, 229-38.

[11] López, FJ.; Molina, DA.; Fernández, CML Development of a photochemically induced fluorescence based optosensor for the determination of imidacloprid in peppers and environmental waters. $\mathrm{Ta}$ lanta, 2007, 72, 991-97.
[12] Cristina, B.; Mónica, F.; Yolanda, P.; Guillermina, F.; Jordi, M. Simultaneous determination of imidacloprid, carbendazim, methiocarb and hexythiazox in peaches and nectarines by liquid chromatography - mass spectrometry. Anal. Chim. Acta, 2002, 461, 10916.

[13] David, K.; Kevin, G.; Derek, C.; Taylor, S.; Dean, T. Non-target effects on aquatic decomposer organisms of imidacloprid as a systemic insecticide to control emerald ash borer in riparian trees. Ecotoxicol. Environ. Saf., 2007, 68, 315-25.

[14] Mahmoodi, NM.; Arami, M.; Limaee, NY.; Gharanjig, K. Photocatalytic degradation of agricultural $\mathrm{N}$-heterocyclic organic pollutants using immobilized nanoparticles of titania. J. Hazard. Mater., 2007, 145, 65-71.

[15] Zheng, W.; Liu, WP.; Wen, YZ.; Lee, S.J. Photochemistry of insecticide Imidacloprid: direct and sensitized photolysis in aqueous medium. J. Environ. Sci. China, 2004, 16, 539-42.

[16] Socías-Viciana, M.; González-Pradas, E.; Saifi, M.; Ureña-Amate, MD.; Flores-Céspedes, F.; Fernández. Pérez, M. The potential removal of imidacloprid from water by heat-treated kerolites. Pest Manag. Sci., 2003, 59, 1162-68.

[17] Young, J.J.; Cynthia, S.; Taein, O. Comparison of zinc oxide nanoprticles and its nano-crystalline particles on the photcatalytic degradation of methylene blue. Mater. Res. Bull., 2006, 41, 67-77.

[18] Lopes, RP.; Urzedo, AP.; Nascentes, CC.; Augusti, R. Degradation of the insecticides thiamethoxam and imidacloprid by zero-valent metals exposed to ultrasonic irradiation in water medium: electrospray ionization mass spectrometry monitoring. Rapid Commun. Mass Spectrom., 2008, 22, 3472-80.

[19] Sundaram, B.; Rai, SK.; Ravendra, N. Determination of the insecticide imidacloprid in water and soil using high-performance liquid chromatography. J. Chromatogr. A, 1997, 787, 271-75.

[20] Jian, P.; Xiao-Xiao, X.; Juan, L. Analysis of pesticide multiresidues in leafy vegetables by ultrasonic solvent extraction and liquid chromatography-tandem mass spectrometry. Ultrason. Sonochem., 2008, 15, 25-32.

[21] Pirard, C.; Widart, J.; Nguyen, B.K.; Deleuze, C.; Heudt, L.; Haubruge, E.; De, Pauw, E.; Focant, J.F. Development and validation of a multi-residue method for pesticide determination in honey using on-column liquid-liquid extraction and liquid chromatography-tandem mass spectrometry. J. Chromatogr. A, 2007, 1152, 116-23.

[22] Serenella, S.; Paola, F.; Danilo, AB.; Patrizia, M. Multiresidue determination of nicotinoid insecticide residues in drinking water by liquid chromatography with electrospray ionization mass spectrometry. Anal. Chim. Acta, 2005, 553, 21-26.

[23] Rongguo, X.; Dongsheng, L.; Hui, Z.; Daren, Y.; Minhua, J.; Takashi, S.; Baodan, L.; Yashi, B. Low temperature growth of uniform $\mathrm{ZnO}$ particles with controllable ellipsoidal morphologies and characteristic luminescence patterns. J. Phys. Chem. B, 2006, 110, 19147-53.

[24] Ramesh, A.; Balasubramanian, M. Kinetics and hydrolysis of fenamiphos, fipronil and triflurolin in aqueous buffer solutions. $J$. Agric. Food Chem., 1999, 47, 3367. 